\title{
ARTICLE
}

\section{Large-Scale FE Analysis of Steel Building Frames Using E-Simulator}

\author{
Tomoshi MIYAMURA ${ }^{1,7, *}$, Makoto OHSAKI ${ }^{2}$, Masayuki KOHIYAMA ${ }^{3}$, Daigoro ISOBE ${ }^{4}$, \\ Kunizo ONDA ${ }^{5}$, Hiroshi AKIBA ${ }^{5}$, Muneo HORI ${ }^{6}$, Koich KAJIWARA ${ }^{7}$ and Tatsuhiko INE ${ }^{7}$ \\ ${ }^{1}$ Dept. of Computer Science, College of Engineering, Nihon University, Koriyama, Fukushima 963-8642, Japan \\ ${ }^{2}$ Dept. of Architecture, Hiroshima University, Higashi-Hiroshima 739-8527, Japan \\ ${ }^{3}$ Dept. of System Design Engineering, Keio University, Yokohama 223-8522, Japan \\ ${ }^{4}$ Dept. of Engineering Mechanics and Energy, University of Tsukuba, Tsukuba 305-8573, Japan \\ ${ }^{5}$ Allied Engineering Corporation, Tokyo 135-0061, Japan \\ ${ }^{6}$ Earthquake Research Institute, The University of Tokyo, Tokyo 113-0032, Japan \\ ${ }^{7}$ Hyogo Earthquake Eng. Research Center, National Research Institute for Earth Science and Disaster Prevention, Miki 673-0515, Japan
}

\begin{abstract}
The results of a high-precision finite element (FE) analysis using the E-Simulator, which is a parallel FE analysis software package for virtual shaking-table tests of civil or architectural structures, are presented for the seismic responses of a 4-story steel frame and a 31-story super-high-rise steel frame. The 4-story frame is a specimen of the full-scale total collapse shaking-table test conducted in 2007 at the Hyogo Earthquake Engineering Research Center of the National Research Institute of Earth Science and Disaster Prevention, Japan. These steel frames are modeled by meshes of hexahedral solid elements. Large strain elastoplasticity is considered in the analyses. It is shown through numerical examples that elastoplastic dynamic responses can be estimated with good accuracy without resorting to macro models such as those involving plastic hinge and composite beam effects.
\end{abstract}

KEYWORDS: E-Simulator, steel building frame, solid element, domain decomposition, parallel computing

\section{Introduction}

The E-Simulator is a parallel finite element (FE) analysis software package for virtual shaking-table tests of civil or architectural structures. ${ }^{1)}$ It is being developed at the Hyogo Earthquake Engineering Research Center (E-Defense) of the National Research Institute of Earth Science and Disaster Prevention (NIED), Japan. ${ }^{2)}$ The prototype of the E-Simulator employs a commercial parallel FE structural analysis software package, ADVENTURECluster, ${ }^{3)}$ which has been extended from the open source version, ADVENTURE_Solid, in the ADVENTURE system. ${ }^{4,5}$ These packages use the domain decomposition method for parallel implementation. The ADVENTURE_Solid adopts the balancing domain decomposition (BDD) method, ${ }^{6,7)}$ which is a substructuring-based linear iterative method with a Neumann-Neumann preconditioner combined with coarse grid correction. On the other hand, the Coarse Grid Conjugate Gradient (CGCG) method ${ }^{8)}$ has been developed originally for the ADVENTURECluster. The CGCG method is a conjugate gradient method combined with domain decomposition. It is preconditioned by motion of the decomposed subdomains. This idea is similar to the coarse grid correction used in the BDD method. However, the CGCG method is not a substructuring-based iterative method, and the computation cost for static condensation in each subdomain using a direct solver is reduced. The ADVENTURECluster can be operated in a massively parallel

*Corresponding author, E-mail:miyamura@cs.ce.nihon-u.ac.jp

(c) 2011 Atomic Energy Society of Japan, All Rights Reserved. computation environment; indeed, it was implemented on Blue Gene/L in 2006 and the work was selected as a finalist in the 2006 Gordon Bell Prizes. ${ }^{3)}$

The E-Simulator enables large-scale analysis to be performed with a very fine mesh of solid elements. In conventional analysis methods for steel building frames, however, macro models such as an empirically defined plastic hinge and fiber model are used. The results of analyses using such macro models depend strongly on the assumptions included in the models, which are made by the intuition of an engineer. In addition, experimental evaluation of the structural components involved is necessary in order to determine appropriate model parameters. On the other hand, only simple material tests are necessary in order to determine the material properties for the constitutive equations used in the solid element.

In the E-Simulator, the constitutive equations and rupture/fracture models for civil and building structures are implemented. However, in the present study, the analyses are carried out using the original ADVENTURECluster in order to evaluate its performance as a platform for the E-Simulator, and the enhanced functions of the material models are not used.

In the following sections, the results of a high-precision FE analysis are presented for the seismic responses of a 4-story steel building frame and a 31-story super-high-rise steel frame. The 4-story frame is a specimen of the full-scale total collapse shaking-table test conducted in September 2007 at E-Defense. ${ }^{9)}$ Preliminary analyses for the 31-story 
frame were described in Ref. 10). These steel frames are modeled by meshes with hexahedral solid elements, and elastoplastic analyses considering large strains are conducted. Note that the maximum absolute value of principal strain in the analyses for the 4-story and 31-story frames are found to be about 0.21 and 0.023 , respectively.

\section{Analysis of 4-Story Steel Frame Model}

\section{Analysis Model}

The FE model for the 4-story frame shown in Fig. 1 is generated using the data and documents distributed for the blind analysis contest. ${ }^{12)}$ All the members and the floor slabs are modeled by 8-node hexahedral solid elements; i.e., the DOFs of each node correspond to three translational displacements, and the displacements in the elements are interpolated by linear shape functions. Figure 2 shows the FE mesh used in the present study. A disadvantage of using hexahedral elements is that automatic mesh generation is impossible for complex geometries, which means that mesh generation requires considerable time and effort. In contrast, fully automatic mesh generation can be conducted for a mesh with tetrahedral finite elements. In this case, however, a huge number of elements are necessary to represent the complex geometry of a steel building frame with many columns and beams that are made of thin plates.

The FE mesh generated by the Noguchi Laboratory at Keio University, Japan, is used as the prototype. The final mesh has 4,746,722 elements, 6,739,853 nodes, and $20,219,559$ DOFs. Plates such as the flanges and webs of beams are divided into at least two layers of solid elements. Each floor slab is also divided into solid elements with two layers. Studs connecting the flange and the slab are omitted in the present model, and the lower surface along the boundary of the slab is directly connected to the upper layer of the flange. Steel bars in the slab are omitted. The size of each element in the longitudinal direction of a beam or a column is approximately $13 \mathrm{~mm}$ near the connections, where severe plastic deformation is expected, while a coarser mesh is used for elements located far from the connections.

Piecewise linear isotropic hardening is used in the constitutive model of the steel material, and its parameters are determined from the uniaxial test results distributed for the blind analysis contest. A bilinear relation is used in the constitutive model of the concrete of the floor slab. The self-weight of the steel is computed based on a mass density of $7.86 \times 10^{3} \mathrm{~kg} / \mathrm{m}^{3}$. In contrast, the mass density of $2.3 \times 10^{3} \mathrm{~kg} / \mathrm{m}^{3}$ of the slab is increased appropriately to include the weights of nonstructural components, anti-collapse frames and stair landings installed in the experimental model.

The elastoplastic dynamic collapse analysis is carried out under two different conditions, referred to as Cases A and B. In Case $A$, the stiffness of the exterior wall is ignored, and the column bases are fixed. In Case B, the stiffness of the exterior wall is modeled by elastoplastic shear springs connecting the flanges of the beams in the upper and lower floors. The appropriate parameters are determined from the experimental results. ${ }^{13)}$ The column bases in Case $\mathrm{B}$ are modeled by rotational springs around the $\mathrm{X}$ - and $\mathrm{Y}$-axes whose rotational stiffness is assigned based on the recommendations of the Architectural Institute of Japan. ${ }^{14)}$ The rotational stiffness around the Z-axis of the column base is 10 times as large as those around the $\mathrm{X}$ - and $\mathrm{Y}$-axes.

Since most of the damping of a steel frame is related to friction and plastification of nonstructural components, the ambiguous equivalent linear damping will be replaced by a more accurate model of the nonstructural components. However, Rayleigh damping is used in the present analyses.

\section{Results}

The four lowest natural periods obtained by eigenvalue analysis for Cases A and B are listed in Table 1. A time-history analysis is carried out for Cases A and B for the three-dimensional input motions associated with the JR-Takatori wave during the 1995 Hyogo-ken Nanbu Earthquake, scaled by a factor of 0.6. The acceleration record measured on the shaking table during the full-scale test is used instead of the numerically scaled ground motion record of the earthquake. Note that the EW, NS, and UD components correspond to the X-, Y-, and Z-directions, respectively. The duration of the motion is $20 \mathrm{~s}$.

In the Rayleigh damping, the damping factors used are 0.02 for the 1st and 4th modes, which are the two lowest

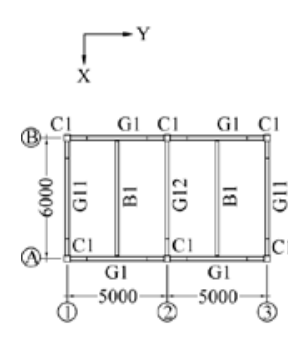

(a) Plan (1st Floor)

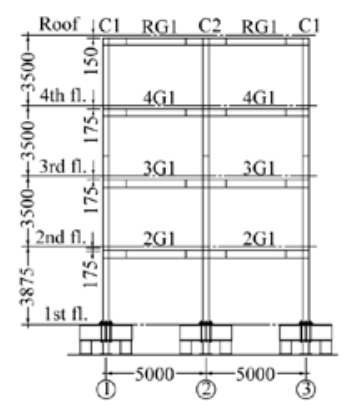

(b) Y-elevation

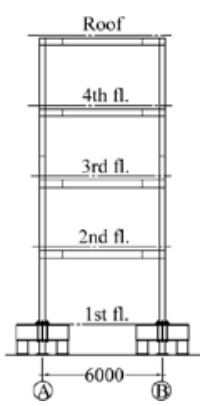

(c) X-elevation
Fig. 1 4-story steel frame model ${ }^{11)}$

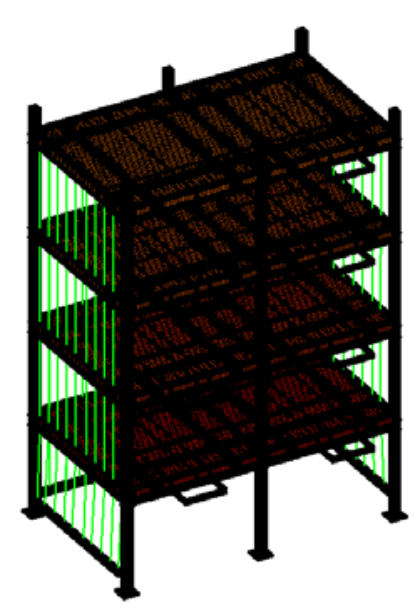

(a) Whole frame

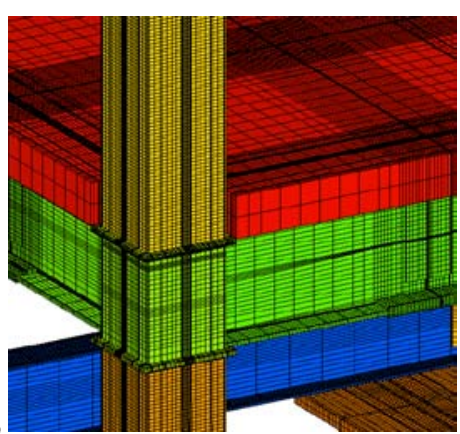

(b) Close-up view
Fig. 2 Finite element mesh of the 4-story steel frame 
modes in the X-direction. The Hilber-Hughes-Taylor method is used for time integration with parameters $\alpha=-0.05, \beta=$ $(1-\alpha)^{2} / 4=0.275625$. In this analysis, the 256 cores (Intel Itanium $1.66 \mathrm{GHz}$ ) of the SGI Altix 4700 (1 node $\times 256$ cores/node) at NIED are used for computation. The computation time is 2,414 s for the static analysis for application of self-weight, and the average computation time is $1,106 \mathrm{~s}$ for one step ( $\Delta t=0.01 \mathrm{~s}$ ) in the time-history analysis.

The time histories of the interstory drift angles and the shear forces of the 1st story are plotted in Figs. 3 and 4, respectively. As shown in Figs. 3(c), 3(d), 4(c) and 4(d), a higher correlation with the experimental results is observed for Case B than for Case A for the period 3 to $5 \mathrm{~s}$, particularly in the X-direction. After $5 \mathrm{~s}$, however, Case B is not consistently better. The behavior of the steel frame after $8.3 \mathrm{~s}$ seems to be almost elastic. The effect of hysteretic damping due to plastic energy dissipation in the exterior wall in Case B is not clearly observed since the magnitude of the drift angle oscillations in Case A decreases more than that in Case B after $8.3 \mathrm{~s}$. The maximum and minimum values of the interstory drift angles are $0.01089 \mathrm{rad}$ and $-0.01357 \mathrm{rad}$ in the X-direction, and $0.02300 \mathrm{rad}$ and $-0.007942 \mathrm{rad}$ in the Y-direction, whereas the experimental results are $0.0121 \mathrm{rad}$ and $-0.0122 \mathrm{rad}$ in the X-direction, and $0.0190 \mathrm{rad}$ and $-0.00933 \mathrm{rad}$ in the Y-direction. Therefore, moderately accurate results are obtained by the numerical analysis. It should also be noted that Fig. 3(b) shows that a residual deformation exists in the Y-direction.

The shear forces of the 1st story (base shear forces) are calculated by the summation of the concentrated mass multiplied by the acceleration at the center of gravity of each floor. The maximum and minimum values of the shear forces of the 1st story are $1142 \mathrm{kN}$ and $-1153 \mathrm{kN}$ in the $\mathrm{X}$-direction, and $1385 \mathrm{kN}$ and $-1229 \mathrm{kN}$ in the Y-direction. Since the experimentally measured values are $1169 \mathrm{kN}$ and $-1173 \mathrm{kN}$ in the $\mathrm{X}$-direction, and $1423 \mathrm{kN}$ and $-1058 \mathrm{kN}$ in the Y-direction, the shear forces are estimated with good accuracy.

Figures 5 and 6 respectively depict the deformation at $6 \mathrm{~s}$ for Cases A and B, which is the point of almost maximum deformation. The deformation is magnified 10 times and the colors represent the distribution of equivalent stress. In Case $\mathrm{B}$, a rotational response occurs because the exterior walls are considered, which leads to uniaxial eccentricity. Large stress is observed around the column base and beam-to-column connections. Figure 7 shows the deformation and equivalent stress for Case A from another viewpoint.

Table 1 Four lowest natural periods for Cases A and B

\begin{tabular}{ccccc}
\hline Case & 1st & 2nd & 3rd & 4th \\
\hline Case A & 0.8389 & 0.8144 & 0.5700 & 0.2702 \\
\hline Case B & 0.8303 & 0.8203 & 0.5555 & 0.2700 \\
\hline
\end{tabular}

(unit: s)

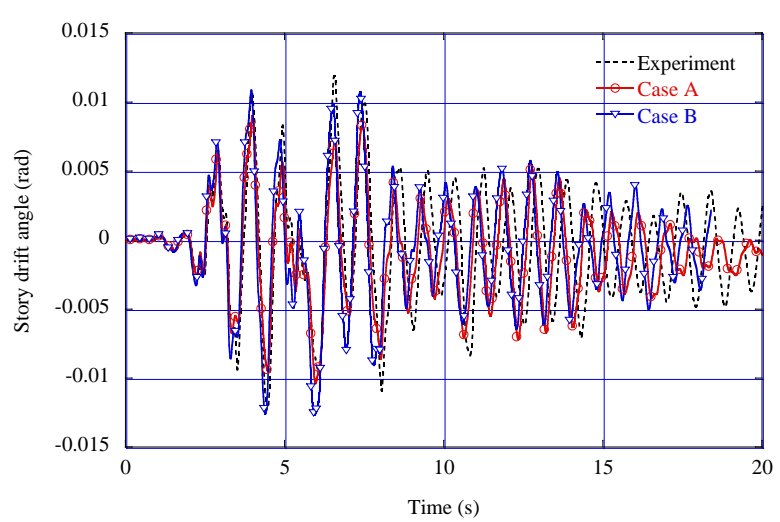

(a) X-direction

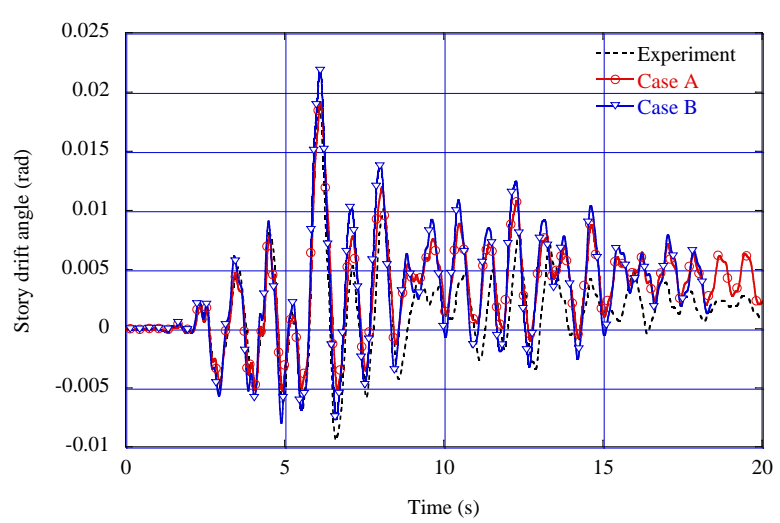

(b) Y-direction

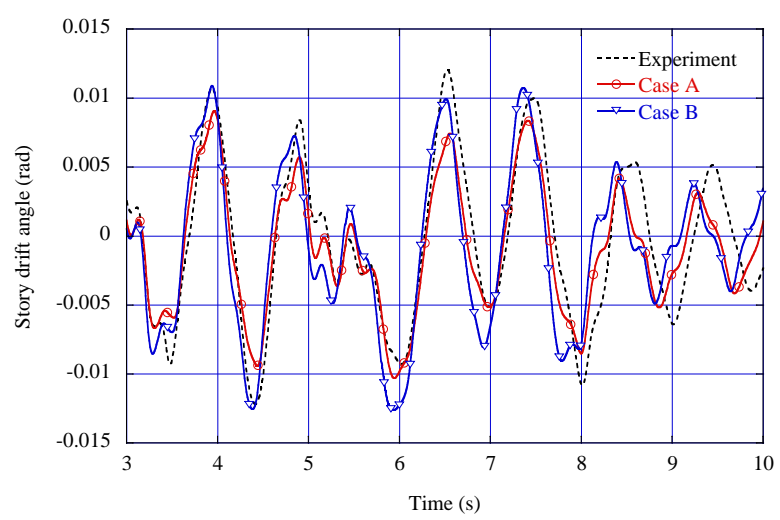

(c) X-direction (magnified for the interval between 3 and $10 \mathrm{~s}$ )

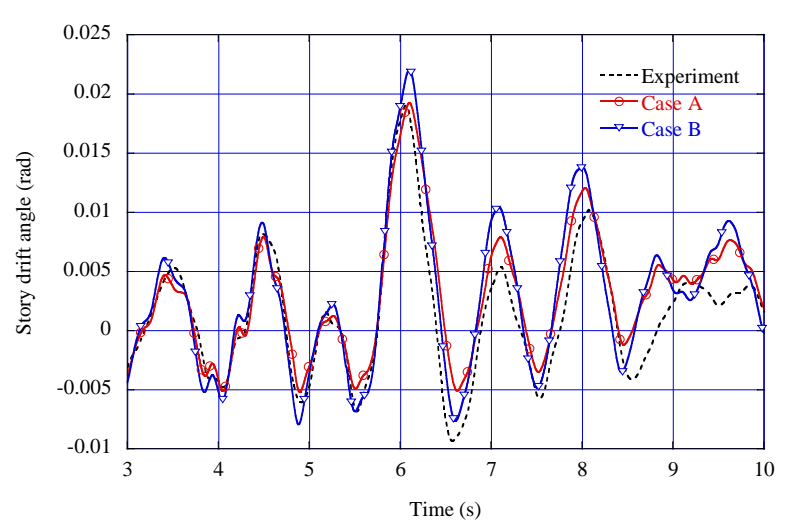

(d) Y-direction (magnified for the interval between 3 and $10 \mathrm{~s}$ )

Fig. 3 Time-history of interstory drift angle of the 1st story. 


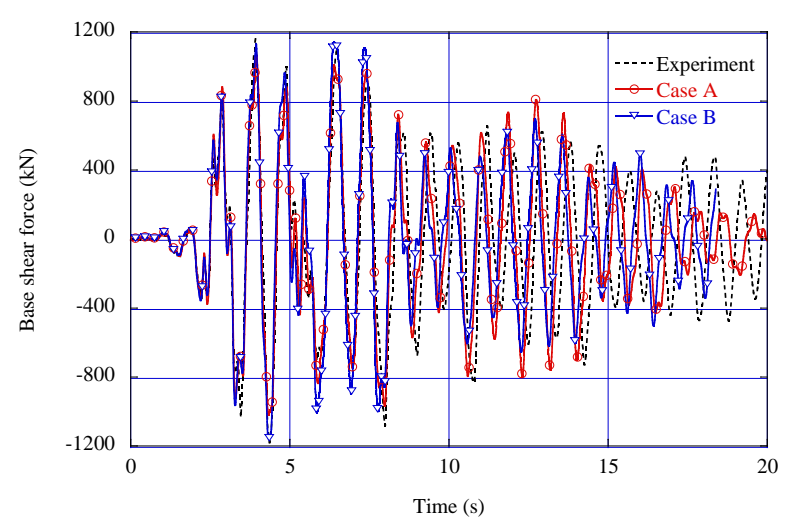

(a) X-direction

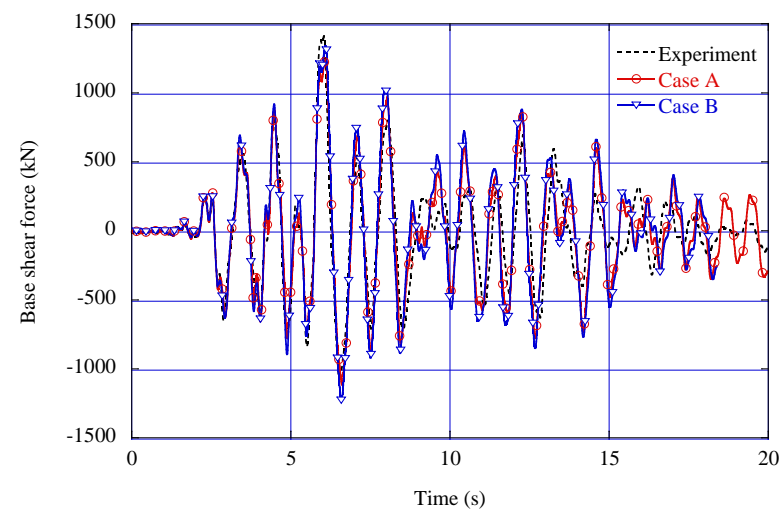

(b) Y-direction

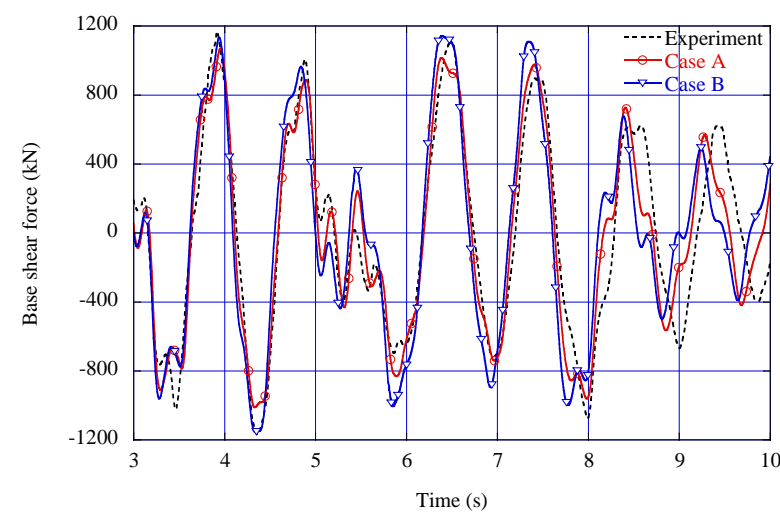

(c) X-direction (magnified for the interval between 3 and $10 \mathrm{~s}$ )

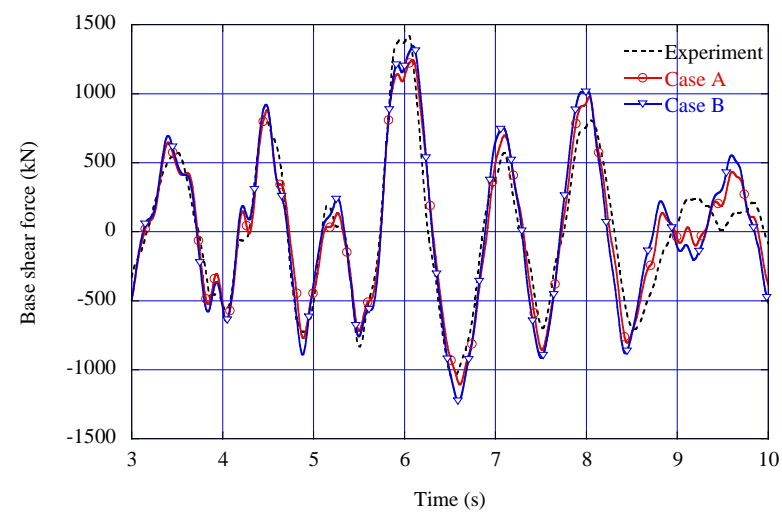

(d) Y-direction (magnified for the interval between 3 and $10 \mathrm{~s}$ )

Fig. 4 Time-history of the shear force of the 1st story.

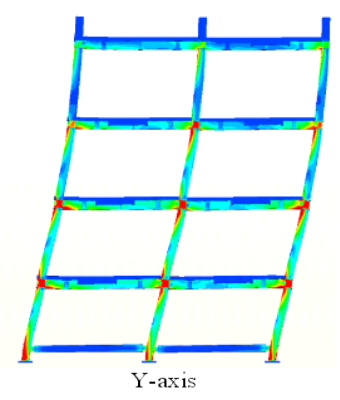

(a) Y-axis

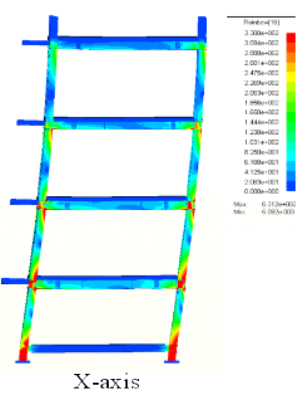

(b) $\mathrm{X}$-axis

Fig. 5 Case A: deformation (magnified 10 times) with distribution of equivalent stress at $6 \mathrm{~s}$.

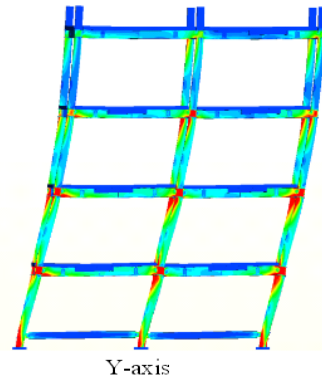

(a) Y-axis

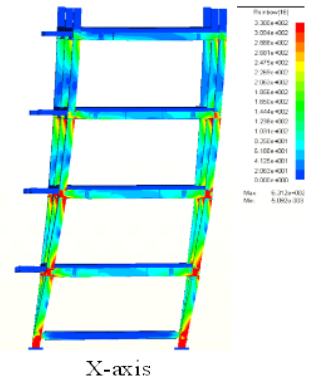

(b) $\mathrm{X}$-axis

Fig. 6 Case B: deformation (magnified 10 times) with distribution of equivalent stress at $6 \mathrm{~s}$.

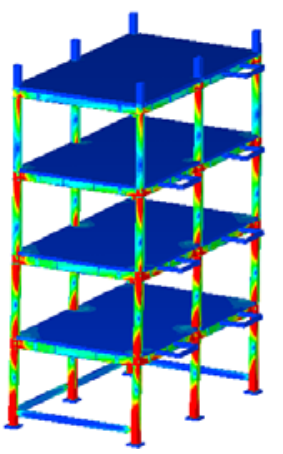

(a) Whole frame

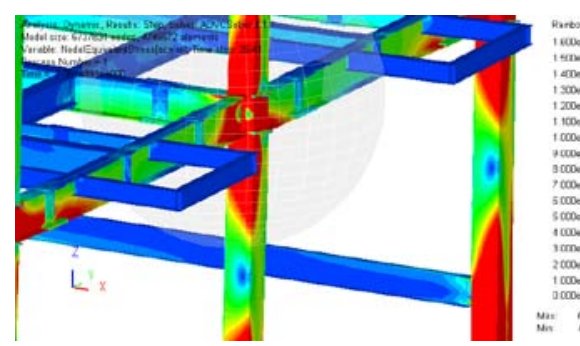

(b) 2nd floor and 1st story

Fig. 7 Distribution of equivalent stress at maximum deformation (Case A).

\section{Analysis of 31-Story Steel Frame Model}

\section{Analysis Model}

A 31-story super-high-rise steel building frame as shown in Fig. 8 has been designed as a specimen for the E-simulator. The frame is a center-core-type 31-story office building. The story height is $5.4 \mathrm{~m}$ for the 1st and 2nd stories, and $4.1 \mathrm{~m}$ for the other stories. The total height is $129.7 \mathrm{~m}$, and the size of the plan is $50.4 \mathrm{~m} \times 36.0 \mathrm{~m}$. Buckling-restrained braces as hysteresis passive dampers are located in the core. Parts of the hexahedral FE mesh are shown in Fig. 9. The mesh has 15,592,786 elements, $24,765,275$ nodes, and $74,295,825$ DOFs. Plates such as the flanges and webs of beams are divided into at least two layers of solid elements. Studs connecting the flange and the slab and steel bars in the slab are omitted in the model, and 
the lower surface along the boundary of the slab is directly connected to the upper layer of the flange. The size of each element in the longitudinal direction of a beam or a column is approximately $70 \mathrm{~mm}$ near the connections while a coarser mesh is used for elements located far from the connections. Note that the size of $70 \mathrm{~mm}$ is larger than that used in the 4-story frame described in Section II.

The materials of the frame are steel for the beams and columns, and reinforced concrete for the slabs. The elastic modulus, yield stress, and Poisson's ratio of the steel are $205 \mathrm{kN} / \mathrm{mm}^{2}, 330 \mathrm{~N} / \mathrm{mm}^{2}$, and 0.3 , respectively, and kinematic hardening with a coefficient of $1 / 1,000$ is used. The slab is assumed to be made of an elastic material, where the elastic modulus and Poisson's ratio are $22.7 \mathrm{kN} / \mathrm{mm}^{2}$ and 0.2 , respectively. The mass density of the steel is $7.86 \times 10^{3} \mathrm{~kg} / \mathrm{m}^{3}$, whereas that of slab is increased by an amount equivalent to the floor loads. The thickness of the slab is $0.1275 \mathrm{~m}$, and the area it covers is $1645.92 \mathrm{~m}^{2}$ for each floor.

The base beams are elastic and have the same sections as those in the 2nd floor; however, the elastic modulus is 5.5 times as large as the standard value to represent the stiffness of the underground structure. The nodes in each column base are connected by rigid beams to a node at the center of the column, which is pin-supported.

\section{Results}

The six lowest natural periods obtained by eigenvalue analysis are listed in Table 2. A time-history analysis is carried out for the three dimensional input motions associated with the JR-Takatori wave during the 1995 Hyogo-ken Nanbu Earthquake without scaling. Note that the EW, NS, and UD components correspond to the X-, Y-, and Z-directions, respectively. The duration of the motion is $10 \mathrm{~s}$ (from 1.7 to $11.7 \mathrm{~s}$ in the original wave). Rayleigh damping is used, with a damping factor of 0.02071 for the 1 st mode. The Hilber-Hughes-Taylor method is used for time integration with parameters $\alpha=-0.05, \beta=(1-\alpha)^{2} / 4=0.275625$. In this analysis, 192 cores (AMD Quad Core Opteron $2.3 \mathrm{GHz}$ ) of the T2K super-computer $(24$ nodes $\times 8$ cores/node) at the University of Tokyo are used. The average computation time for one time step ( $\Delta t=0.01 \mathrm{~s})$ is $12,312 \mathrm{~s}$. However, since the time when the simulations described in the present paper were carried out, the computational performance has been improved, and speeds of more than four times higher are now possible with the latest version of the software. $^{15)}$

Figure 10 shows the time history of the nodal displacement at a node in the corner column on the 31st floor. Figure 11 shows the deformation and distribution of the equivalent stress at a time of $4.99 \mathrm{~s}$. Figure 12 shows the distribution of the equivalent plastic strain at a time of $6.21 \mathrm{~s}$,

Table 2 Six lowest natural periods for 31-story frame

\begin{tabular}{cccccc}
\hline 1st & 2nd & 3rd & 4th & 5th & 6th \\
\hline 3.253 & 2.870 & 2.616 & 1.032 & 0.951 & 0.850 \\
\hline & & & & & (unit: s)
\end{tabular}
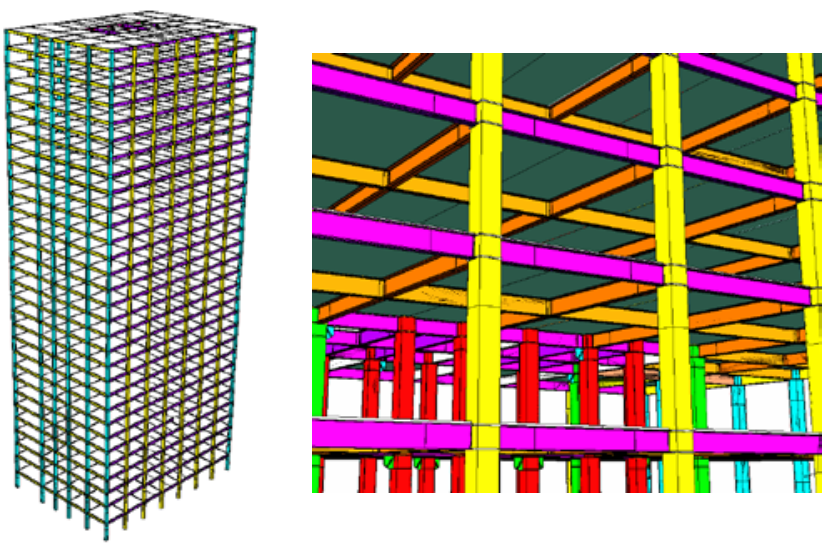

Fig. 8 3D CAD model of 31-story steel frame
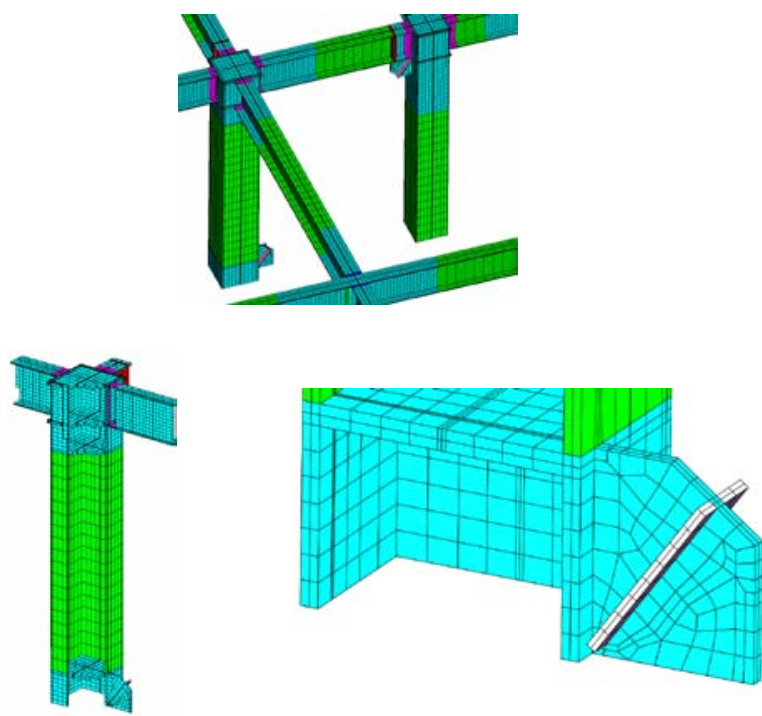

Fig. 9 Parts of hexahedral finite element mesh of 31-story frame

when the displacement at the corner column on the 31st floor is almost at its maximum (see Fig. 10).

\section{Conclusion}

The results of high-precision FE analysis using the E-Simulator, which is a parallel FE analysis software package for virtual shaking-table tests of civil or architectural structures, are presented for the seismic responses of a 4-story steel building frame and a 31-story super-high-rise steel frame. It is shown through numerical examples that elastoplastic dynamic responses can be estimated with good accuracy using high-precision FE analysis without resorting to macro models such as those involving plastic hinge and composite beam effects.

\section{Acknowledgment}

This study is part of the E-Defense Seismic Experimental Study and Simulation System Construction Project conducted by the E-Simulator Production Committee. The authors acknowledge valuable contributions from the com- 


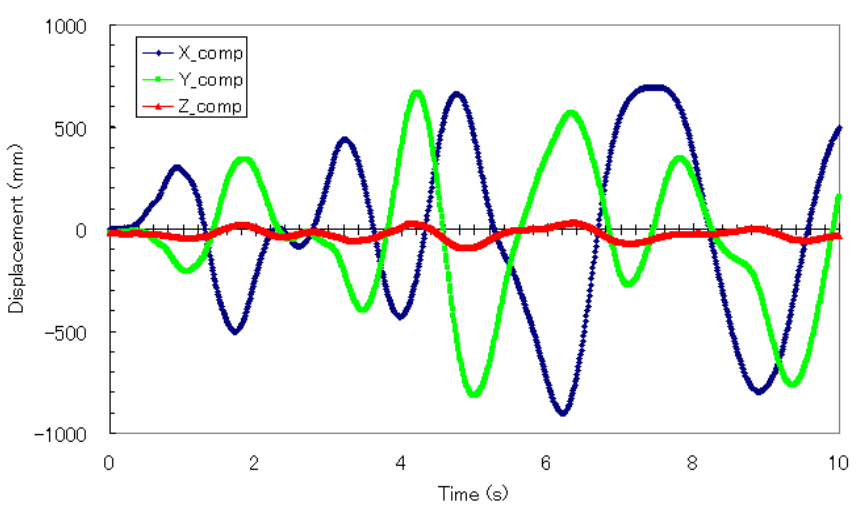

Fig. 10 Time history of nodal displacement at a node in the corner column on the 31st floor

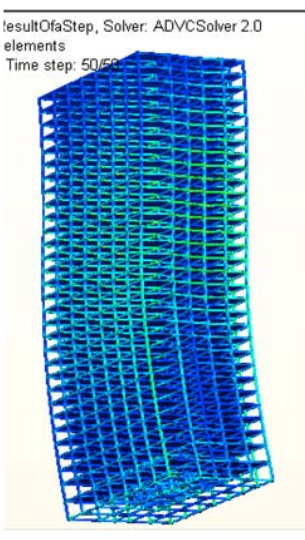

(a) Whole frame

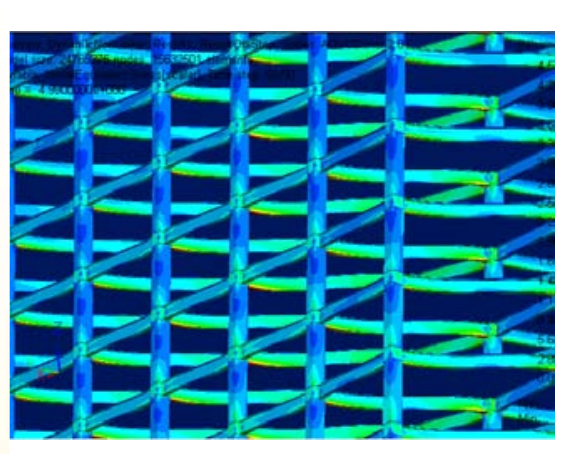

(b) Close-up view
Fig. 11 Deformation (magnified 20 times) with distribution of equivalent stress at $4.99 \mathrm{~s}$

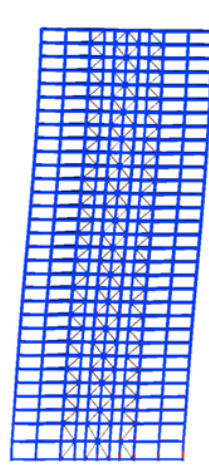

(a) Whole frame

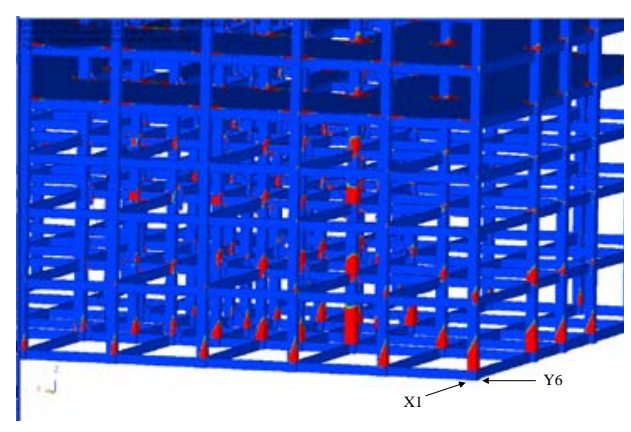

(b) Close-up view
Fig. 12 Deformation (magnified 10 times) with distribution of equivalent plastic strain at $6.21 \mathrm{~s}$

mittee members, and financial support from NIED. The contribution of Mr. Kiyoshi Yuyama and Dr. Tomonobu Ohyama from Allied Engineering Corporation with regard to computation and mesh generation is also gratefully acknowledged.

The authors also acknowledge valuable information obtained from the NEES/E-Defense collaborative research program on steel structures, which was pursued by the
Analysis Method and Verification Working Group and Building Collapse Simulation Working Group.

\section{References}

1) M. Hori, H. Noguchi, T. Ine, "Project report of development of numerical shaking table coping with E-Defense," JSCE J. Earthquake Eng., 29, 1420-1425 (2007), [in Japanese].

2) Website of Hyogo Earthquake Engineering Research Center (E-Defense), National Research Institute of Earth Science and Disaster Prevention (NIED), Japan, http://www.bosai.go.jp/hyogo/ehyogo/index.html

3) H. Akiba et al., "Large scale drop impact analysis of mobile phone using ADVC on Blue Gene/L,” Proc. International Conference for High Performance Computing Networking and Storage (SC06), Tampa (2006).

4) Website of ADVENTURE project, http://adventure.sys.t.u-tokyo.ac.jp/

5) S. Yoshimura, R. Shioya, H. Noguchi, T. Miyamura, “Advanced general-purpose computational mechanics system for large scale analysis and design," J. Comput. Applied Math., 149, 279-296 (2002).

6) J. Mandel, "Balancing domain decomposition," Comm. Numer. Meth. Eng., 9, 233-241 (1993).

7) M. Ogino, R. Shioya, H. Kawai, S. Yoshimura, "Seismic response analysis of nuclear pressure vessel model with ADVENTRUE System on the Earth Simulator,” J. Earth Simulator, 2, 41-54 (2005).

8) M. Suzuki, T. Ohyama, H. Akiba, S. Yoshimura, H. Noguchi, "Development of fast and robust parallel CGCG solver for large scale finite element analyses," Trans. Japan Soc. Mechanical Engineers, A68, 1010-1017 (2002), [in Japanese].

9) K. Kasai, Y. Ooki, S. Motoyui, T. Takeuchi, E. Sato, "E-Defense tests on full-scale steel buildings: Part 1 - Experiments using dampers and isolators," Proc. Structures Congress 2007, ASCE, Long Beach (2007).

10) M. Ohsaki, T. Miyamura, M. Kohiyama, M. Hori, H. Noguchi, H. Akiba, K. Kajiwara, T. Ine, "High-precision finite element analysis of elastoplastic dynamic responses of super-highrise steel frames,” Earthquake Eng. Struct. Dynam., 38[5], 635-654 (2009).

11) M. Tada, M. Ohsaki, S. Yamada, S. Motoyui, K. Kasai, "E-Defense tests on full-scale steel buildings: Part 3 - Analytical simulation of collapse,” Proc. Structures Congress 2007, ASCE, Long Beach (2007).

12) M. Ohsaki, K. Kasai, Y. Matsuoka, J. Y. Zhang, "Results of recent E-Defence tests on full-scale steel building: Part 2, Collapse simulation and blind analysis contest," Proc. Structures Congress 2008, ASCE, Vancouver (2008).

13) Y. Matsuoka, T. Matsumiya, K. Suita, M. Nakashima, “Test on seismic performance evaluation of exterior ALC walls with opening: E-Defense experimental projects for steel buildings Part 14," Summaries of Technical papers of Annual Meeting Architectural Institute of Japan, C-1, 1081-1082 (2007), [in Japanese].

14) Architectural Institute of Japan, Recommendations for the Design and Fabrication of Tubular Structures in Steel, Architectural Institute of Japan (AIJ) (1990), [in Japanese].

15) H. Akiba, K. Hashizume, T. Miyamura, "Large-scale nonlinear dynamic analysis of super-highrise steel frame using T2K and E-Simulator," Supercomputing News, Information Technology Center, The University of Tokyo, 13[3] (2011), [in Japanese]. 